\title{
PREVALENCIA DE Cryptosporidium sp EN TERNEROS DE LOS ALREDEDORES DE TACNA - PERÚ
}

Luis Lloja Lozano ${ }^{1}$

\section{HEMEROTECA CENTRAL UNIBG}

\section{INTRODUCCIÓN}

Cryptosporidium es un protozoario parásito conocido desde inicios del presente siglo y descrito por primera vez por Tizzer en 1907, quien lo observó en cortes histológicos de glándulas gástricas de ratones de laboratorio que no presentaban sintomas.

Este parásito está ubicado en el Phylum Apicomplexa y en el orden Eucoccidia, por lo que está relacionado taxonómicamente a otros coccidios que infectan a humanos tales como: Isospora belli, Taxoplasma gondii y Plasmodium spp. Se diferencia de éstos, sin embargo, por presentar desarrollo completo dentro de un solo huésped, carecer de huésped específico y estar confinado a la superficie de las microvellosidades más que al citoplasma de las células epiteliales.

La forma infectante para los huéspedes es el oocisto maduro. Esta forma evolutiva ingresa por vía oral; y, al disolverse la pared quistica por acción de los jugos digestivos, se liberan los esporozoitos que se ubican en la superficie de las microvellosidades intestinales. Alli se lleva a cabo ciclos de reproducción esquizogónica y gametogónica, dando lugar a la producción de oocistos que al desprenderse hacia la luz intestinal son evacuados con las heces. Cualquier mecanismo de contaminación fecal de agua y los alimentos servirá para infectar a otros huéspedes.

Las criptosporidiosis en el hombre y los animales domésticos, entre ellos los vacunos, se manifiestan por gasteroenteritis y muchas diarreas entre los dos a siete dias después de la infección.

En el Perú se ha llevado a cabo algunas investigaciones sobre criptosporidiosis, la mayoría de las cuales estuvieron orientadas a buscar al agente

1. Biólogo. En colaboración de E Nina y $\vee$. Machaca etiológico en las heces fecales humanas, y sólo dos en heces fecales diarreicas de terneros criados en la campiña de Cajamarca y en los alrededores de la ciudad de Trujillo, encontrándose al parásito en un 12.24 y $53.20 \%$ respectivamente. Es necesario seguir ampliando las investigaciones sobre criptosporidiosis en animales domésticos del Perú, especialmente en vacunos, debido a que su crianza es una actividad económica importante para un sector de la población. En la ciudad de Tacna no se ha reportado hasta la fecha ningún trabajo acerca de la frecuencia de este parásito en terneras, por lo que se plantea la siguiente investigación, con el fin de determinar la presencia y frecuencia de Cryptosporidium $s p$ en terneros, con cuadro de deposiciones normales y diarreicas, de tres a setenticinco dias de edad.

\section{MATERIAL Y MÉTODOS}

El trabajo se basó en el análisis de 65 muestras fecales de terneras de tres a setentaicinco dias de edad, criados en los alrededores de la ciudad de Tacna.

Las muestras fueron colectadas durante los meses de noviembre de 1994 a marzo de 1995. El trabajo se realizó en dos etapas:

\section{PRIMERA ETAPA: Trabajo de Campo}

Las heces obtenidas por defecación natural del ternero o estimulación de la zona rectal introduciendo el dedo indice previamente protegido con una bolsa de polietileno. Las heces se depositaron inmediatamente en vasos descartables estériles previamente rotulados, protegiéndolos posteriormente con bolsas de polietileno para ser trasladados al laboratorio de biología de la Universidad Nacional Jorge Basadre Grohmann, para su respectivo análisis.

\section{SEGUNDA ETAPA: Trabajo de Laboratorio}

Las muestras fueron procesadas en el 
laboratorio, después de algunas horas, durante los cuales se mantenian conservadas en dicromato de potasio al $2 \%$ y refrigeración, hasta su procesamiento.

Cada una de las muestras fueron concentradas por el método de Teleman modificada y posteriormente coloreadas con el método de KINYOUN modificada.

La identificación de los oocistos se hizo mediante la observación microscópica de su forma, tamaño y color (por la propiedad que presentan en ácido alcohol resistente).

\section{RESULTADOS}

En las 65 muestras coprológicas examinadas se determinó que el $40 \%$ fueron positivas a la presencia de Cryptosporidium $s p$.

La frecuencia de Cryptosporidium en terneras que presentaban o no cuadros diarreicos varia desde 0.00 al $61.54 \%$, siendo la zona de Magollo lateral 2 la que presenta un alto porcentaje de infección.

En la tabla 2 se presenta la frecuencia de Cryptosporidium $s p$ de acuerdo a la edad de los terneros, siendo el rango de 12 a 20 dias el de mayor prevalencia, seguido por las de 66 a 74 dias con porcentajes de 100 a $60 \%$ respectivamente.

Los oocistos de Cryptosporidium $s p$ fueron identificados por la caracteristica de su diámetro promedio de $4.9 u$, o incluso mayor, y su coloración que presentaban por ser ácido alcohol resistente.

\section{DISCUSIÓN}

La frecuencia de Cryptosporidium $s p$ encontrada en Tacna es del $40 \%$ (tabla 1), el cual es elevado con respecto a lo informado previamente en terneros de otros paises como Chile. Dinamarca y Banglsdesh en donde se hallaron porcentajes de parasitismo entre 12.8 y $18.9 \%$. En el Perú sólo es inferior el porcentaje encontrado en la ciudad de Trujillo; el resultado de Tacna señalaria una alta morbilidad debido probablemente a las condiciones climáticas-estacionales favorables para la transmisión del parásito y que están presentes en nuestra localidad, por cuanto la toma de muestras se realizó en los meses de verano, lo que ratificaría la tesis de que el parásito se transmite mayormente en los meses calurosos.

La alta frecuencia encontrada en algunas zonas, por ejemplo: Magollo lateral 2, Sama Las Yaras y Cooperativa 28 de Agosto, con $61.54,50.0$ y $41.94 \%$ respectivamente (tabla 1 ), indicaria que estos carecen
TABLA N ${ }^{\circ} 01:$ Frecuencia de Cryptosporidium sp. según la zona de muestreo entre noviembre de 1994 a marzo de 1995 en los alrededores de. Tacna.

\begin{tabular}{|l|c|c|c|}
\hline \multicolumn{1}{|c|}{ ZONA } & $\begin{array}{c}\text { TERNEROS } \\
\text { EXAMINADOS }\end{array}$ & $\begin{array}{c}\text { TERNEROS } \\
\mathrm{N}^{\circ}\end{array}$ & $\begin{array}{c}\text { NFECTADOS } \\
\%\end{array}$ \\
\hline SAMA GRANDE "CORUCA" & 6 & 00 & 0.00 \\
SAMA LAS YARAS & 6 & 03 & 50.00 \\
YARADA BAJA Km. 23 & 9 & 02 & 22.22 \\
COOPERATIVA 28 DE AGOSTO & 31 & 13 & 41.94 \\
MAGOLLO LATERAL & 13 & 08 & 61.54 \\
\hline TOTAL & 65 & 26 & 40.00 \\
\hline
\end{tabular}

TABLA N ${ }^{\circ}$ 02: Frecuencia de Cryptosporidium sp. de acuerdo a la edad entre noviembre de 1994 a marzo de 1995 en los alrededores de Tacna.

\begin{tabular}{|c|c|c|c|}
\hline EDAD EN DIAS & $\begin{array}{c}\text { TERNEROS } \\
\text { EXAMINADOS }\end{array}$ & $\begin{array}{c}\text { TERNEROS } \\
\mathrm{N}^{\circ}\end{array}$ & $\begin{array}{c}\text { NFECTADOS } \\
\%\end{array}$ \\
\hline $3 \cdot 11$ & 9 & 03 & 33.33 \\
$12 \cdot 20$ & 3 & 03 & 100.00 \\
$21 \cdot 29$ & 1 & 00 & 0.00 \\
$30 \cdot 38$ & 15 & 05 & 33.00 \\
$39 \cdot 47$ & 4 & 01 & 25.00 \\
$48 \cdot 56$ & 0 & 00 & 0.00 \\
$57-65$ & 18 & 05 & 27.78 \\
$66-74$ & 15 & 09 & 60.00 \\
\hline TOTAL & 65 & 26 & 40.00 \\
\hline
\end{tabular}

TABLA N ${ }^{\circ}$ 03: Frecuencia de Cryptosporidium sp. según sexo entre noviembre de 1994 a marzo de 1995 en los alrededores de Tacna.

\begin{tabular}{|c|c|c|c|}
\hline EDAD EN DIAS & $\begin{array}{c}\text { TERNEROS } \\
\text { EXAMINADOS }\end{array}$ & $\begin{array}{c}\text { TERNEROS } \\
\mathrm{N}^{\circ}\end{array}$ & $\begin{array}{c}\text { NFECTADOS } \\
\%\end{array}$ \\
\hline HEMBRA & 31 & 11 & 35.48 \\
MACHO & 34 & 15 & 44.12 \\
\hline TOTAL & 65 & 26 & 40.00 \\
\hline
\end{tabular}

de un adecuado mantenimiento de higiene en los establos, o tal vez se debe al desconocimiento de la infección cryptosporidiana por parte de los encargados del área veterinaria, lo que implica un manejo deficiente de los mecanismos de control de enfermedades de tipo entérico.

Aunque la cantidad de muestras analizadas durante el tiempo que duró la investigación, no podría ser suficiente como para inferir su relación con la edad, cabe resaltar algunos resultados (tabla 2 ). 
La infección sugiere ser muy importante en los terneros cuyas edades están comprendidas entre 12 a 20 dias, no sólo por la alta frecuencia de infección encontrada, sino, además, porque dichos animales mostraron un marcado cuadro clínico de diarrea, debido probablemente a que la enfermedad se encontraba en su periodo patente y porque a esta edad son más sensibles a la infección por Cryptosporidium $s p$.

Por otro lado, en los animales cuyas edades fueron de 66 a 74 dias, la frecuencia elevada se explicaria porque dichos terneros reciben otro tipo de alimentación, además de ser agrupados junto a vacunos de mayor edad, lo que indica que son expuestos a una mayor contaminación.

Es necesario señalar que, no necesariamente los oocistos se encuentran presentes en heces

\section{REFERENCIAS BIBLIOGRÁFICAS}

ARAYA, J; GONZALES, J.; SAGUA, H., OLIVARES; W. RIMASSA, C. y M. VIDELA. 1987. Cryptosporidiosis en el norte de Chile. Bol. Chil. Parasitol. 42:7-11.

ATIAS, A. y A. NEGHME. 1985. Parasitologia Clínica. 2a. Edic. Edit. Mediterráneo. Santiago-Chile. pp 509

BEAVER, P.; JUNG, R. y E. CUPP. 1986. Parasitologia Clínica. 2da.Ed. Edit. SALVAT Editores S.A. Barcelona - España. pp. 742 .

CASTILLO, O. 1988. Frecuencia de Cryptosporidium spy Gardia lamblia en niños con y sin diarrea en la provincia de Trujillo. Fac. de CC.BB. U.N.T.

CURRENT, W.; STEVE, J y T. HAYNES. 1986. The life cycle of Cryptosporidium baileyi n. sp. (Apicomplexa, Cryptosporidiidae) infecting Chickens. J. Protozool. 33(2):289-296

CURRENT, W. y P. LONG. 1983. Development of Human and calf Cryptosporidium in chicken Embryos. The J. of Infectious Diseases. 148(6):1108-1113.

ESCALANTE, A. 1989. Prevalencia de Cryptosporidium sp en terneros Holstein de la campiña de Cajamarca. Tesis Título de Médico Veterinario. Fac. de CC. Veterinarias U.N.C. pp. 30 .

FINEGOLD, S. y E. BARON. 1989. Diagnóstico Microbiológico. $7 \mathrm{ma}$. Ed. Edit. Médica Panamericana S.A. Bns. Aires. pp. 651

HEINE, J; HARLEY, W. y B. DOUGLAS, 1984. Persistent Cryptosporidium Infections in Congenitally diarreicas, ya que también estos fueron encontrados en heces sólidas y formadas, lo que sugiere un estado asintomático en el ternero, probablemente debido al pequeño número de oocistos presentes en él.

Es necesario resaltar que aparte del trabajo realizado, el cual constituye el primer reporte de frecuencia de Cryptosporidium $s p$ en la ciudad de Tacna y alrededores, se debe efectuar más investigaciones relacionadas con este parásito en lo concerniente a fuentes de contaminación, variación estacional de la infección, que permitan hacer ensayos terapéuticos experimentales a fin de encontrar algún fármaco específico para el tratamiento de la criptosporidiosis; además, se deben realizar estudios sobre su asociación con otros agentes de diarrea y preveer medidas profilácticas para el control de esta infección.

Athymic. (Nude) Mice. Infections and Inmunity. 43(3):856-859.

KIRPATRICK, C. y J. FARREL. 1984. Cryptosporidiosis. Compend. Contin. Edit. Pract. Vet. 6(3):154-164

LYNCH, M; RAPHAEL, S; MELLOR, L. SPARE, P. y M. INWOOD. 1987. Métodos de laboratorio. Vol. 2. 2da Ed. Edit. Interamericana S.A. México D.F. pp. 1522.

MARCIAL, M. y J. MADARA. 1986. Cryptosporidium: cellular localization, Structural Analysis in Guinea Pigs and Suggestion of Protozoan Transport by M Cells. Gastroenterology. 90:583-594.

PEARSON, G.; LOGAN, E. y M. McNULTI. 1982. Distribution of Cryptosporidia within the gastrointestinal tract of young calves. Research in Veterinary Science. 33:228231.

QUIPUSCOA, S.; HERNANDEZ, S. y C. MORENO. 1988. Presencia de Cryptosporidium sp y Giardia lamblia asociados en heces diarreicas en niños de la provincia de Chiclayo-Perú. Libro Resúmen IX Cong. Nac. de Biologia. Piura-Perú.

SOAVE, R. y D. ARMSTRONG. 1986. Cryptosporidium and Criptosporidiosis. Reviews of Infectious Diseasses. 8(6):1012-1022.

TZIPORI, S. 1983. Criptosporidiosis in animals and humans. Microbiological Review. 47(1):84-96

TZIPORI, S. 1985. Cryptosporidium: Notes on Epidemiology and Pathogenesis. Parasitology Today. 1(6):159-165. 